Article

\title{
Reviewing the Inclusion of Artists' Holograms in the Permanent Collections of Fine Art Museums
}

\author{
Sydney Dinsmore \\ Independent artist, Hong Kong, China; sydney.dinsmore@gmail.com \\ Received: 10 August 2019; Accepted: 1 November 2019; Published: 4 November 2019
}

\begin{abstract}
Opening in 1976 with the exhibition, "Through the Looking Glass", the Museum of Holography $(\mathrm{MOH})$ emphasized from the beginning the importance of artistic holography with the inclusion of several holograms by artists whose primary practice was holography, articulating for the first time a distinction between artists, scientists and technicians. While the scientific and engineering principles underlying the technology could educate a public, holograms made by artists provided the visual syntax for the creative possibilities holography could offer. The $\mathrm{MOH}$ continued to encourage and support artists' work throughout its history, amassing a large collection of holograms representative of the most prolific period of artistic activity from the mid 1970s to the mid 1980s. The Massachusetts Institute of Technology Museum (MIT Museum) in Boston acquired the entire archive including artistic and technical holograms as well as all related materials when the $\mathrm{MOH}$ closed in 1992. This paper will seek to explore whether the medium of holography within the visual arts has led to fine art museum acquisitions in the intervening decades.
\end{abstract}

Keywords: holography; hologram; laser transmission hologram; white light reflection hologram; Multiplex hologram; installation

\section{Introduction}

From the 1960s, gallery exhibitions of holography featured both artists who were dominant forces in the world of artistic holography and established artists whose occasional holographic work for site-specific installations or projects was outsourced to studio production facilities. Concurrently, there were recognized distinctions between galleries and museums that were dedicated to exhibitions of holography such as the $\mathrm{MOH}$ and galleries whose artists included holograms in their exhibitions. By the 1980s, a few artists whose primary medium was holography had made the transition into the wider art world and were exhibited in art museums. Recently, there have been donations to fine art museums of holograms by internationally acclaimed artists who experimented with holography as a tool for dimensional image making but whose formal disciplines were in other forms of expression.

In a 2012 Canadian newspaper review in the Globe and Mail, culture journalist, Sarah Nicole Prickett, wrote, "[a]nd so do holograms, which already give the appearance of having time-travelled from the past's idea of today, have less than a century to go? Or will they flicker in and out, trendily, never surpassing kitsch?" (Prickett 2012).

Fifty-five years ago, artists glimpsed the first hologram titled, "Train and Bird," by American scientist Emmett Leith. Ever since, the imaging possibilities of holography have intrigued artists from various disciplines and practices. The $\mathrm{MoH}$ was opened in 1976 to provide a focus to both the science and emerging art of what was then a new visual technology. While holograms were collected by museums outside the dedicated centers for holographic art, holography has not received widespread recognition as an art form. Reading several articles by writer Sean F. Johnston, Professor of Science, Technology and Society, at the University of Glasgow, it appears that a confluence of factors, including the perception that art holography had come late to the "art and technology movement in the 1960s" 
formed the accepted rationale about the lack of a formal collections policy for Holographic Art in most museums (Johnston 2009).

The Metropolitan Museum of Art in New York sets out its acquisition policy, in part, in these terms, "[c]urators should propose exceptional works of art for acquisition to the collection that significantly further the Museum's stated mission. All works should be in, or capable of being returned to, an acceptable state of preservation, unless the deteriorated physical condition is integral to the meaning of the work. The Museum must be able to display, store, and care for the proposed acquisition according to generally accepted museum practices." From this mission statement, it is possible to conclude that the collection by museums of holographic art mirrors the collection policy criteria for any other artwork.

The Getty Research Institute, as part of the Photography collection of the J. Paul Getty Museum in Los Angeles, announced in March 2019 the acquisition of 105 glass plate holograms by 20 artists produced in the 1990s. The donation of 89 laser viewable masters and 16 white light reflection holograms was conceived in collaboration with C-project, a holography studio then operating in New York. In describing the acquisition, Senior Curator of Photography at the J. Paul Getty Museum, Jim Ganz said, "[w]e are pleased to add these visually compelling and artistically significant holograms of the late 20th century to our photograph collection, which has such great depth in 19th-century stereography, including examples by Carleton Watkins, Eadweard Muybridge, Mathew Brady, Roger Fenton, Francis Frith, and Adolphe Braun ... " (Ganz 2019). thereby viewing holograms as an extension of 19th century stereograms within the larger domain of photography.

While the properties of holograms are radically different from photographic stereograms, these hologram acquisitions must fit within the context of a museum's existing collection and provide meaning to the donated artworks within a medium that often slips through the cracks of art and science. Donations and bequests often provide a crucial boost to a collection. Most fine art museums are non-profit organisations with tight operating budgets that depend on government grants, admissions revenue, investment and donations. Few museums have budgets that would allow for the outright purchase of art. Reviewing the Getty donation, all of the artists' works included fit the demanding criteria of a museum donation; importantly it's provenance including the artwork or artist's exhibition history, any critical writing and previous ownership.

\section{Background}

From the 1960s, holography attracted practitioners from all areas of art and science. The galleries and museums that opened in the 1970s specializing in holography were very popular. To explain the emerging art form, technical explanations were offered addressing the illusion of dimensionality and corresponding parallax, that wide horizontal angle of view that set it apart from two-dimensional imagery. Holography was often compared to other media. The pioneering holography artist, Margaret Benyon, quoted Ian Lancaster in her 1994 PhD thesis, How Is Holography Art? "There is still considerable ignorance in the art area about holography, and about what it can and can not do. Judgments and expectations learned from more familiar media are often applied to holography, with damaging results. Many people are not receptive perceptually, emotionally or intellectually to the achievements of holographic artists, because they fail to understand that holography is a medium in its own right, with its own unique characteristics" (Benyon 1994).

The tantalizing promise of being able to create unique dimensional works where the figure or object could be seen in its original physical manifestation was key to the engagement of many artists experimenting with the potential of holography. From the beginning there were established distinctions between artists whose primary medium was holography and had transitioned into the wider art world and recognized artists who chose to experiment with holography but whose formal disciplines and studio practice were in other forms of expression. These artists came to holography to render their existing ideas dimensionally as other media, key to their developing practice, could not provide this opportunity. These distinctions were further refined to encompass the question of whether artists 
making holographic art and light related installations were creating works in their own studios or out sourcing production. Ironically, the artists whose works have recently been acquired by fine art museums have for the most part not been artists whose discipline is primarily holography. Despite its promise and with few exceptions, the mainstream galleries were not exhibiting holograms unless those artists were already in their stable and that trend continues today.

\section{The Importance of the Non-Holographer}

Salvador Dali collaborated with Selwyn Lissack whose company, International Holographic Corp., created several holograms for the artist between 1971-75. Dali said, "[a]ll artists, ... have been concerned with three dimensional reality since the time of Velasquez, and in modern times, the analytic cubism of Picasso tried again to capture the three dimensions of Velasquez. ... with the genius of (Dr. Dennis) Gabor, the possibility of a new Renaissance in art has been realized with the use of holography" (Chimera n.d.). These holograms are still in the collection of the Dali Museum in Pubol, Spain.

Lissack understood that to introduce holography to the art world required a name artist. His perception rings true today. The holograms selected for museum exhibitions and entering major collections are 20-40 years old, created by internationally established artists and typically acquired to fill out 20th century collections of photography. With the Getty Museum acquisition, it is a progressive step forward that curators are proposing and fine art museum boards are approving the purchase of artists' holograms to add to their contemporary holdings. While museums such as the Victoria and Albert Museum in London, England, had been at the forefront of acquiring examples of art holography, most recently with the donation in 2015 of Dr. Paula Dawson's 2006, hybrid hologram of Dr. John Gage, few international museums have been ready to add holograms to their collections. Putting aside the important questions of archival storage, display and promotion, this lack of inclusion into institutional collections neglects a formative element in the developing history of technological art. There are many artists working in holography today whose practices transcend the obvious tropes of light, colour, and dimensionality.

In the 1990s, American collectors of contemporary art, Guy and Nora Barron, were investors in C-Project, a unique collaboration between the New York holography studio of Matthew Schreiber and twenty noted artists from various creative disciplines including sculptor Louise Bourgeois, painters Chuck Close and Ed Ruscha, and light artist James Turrell. These holograms were originally recorded as laser viewable images. In 2017, several were later transferred to white light viewable reflection holograms, a type of hologram that allows it to be mounted on a wall and lighted from above.

While the Turrell holograms of light recordings have been widely exhibited in galleries and museums, the holograms from C-Project that have generated particular interest are a series of eight images, called "Untitled," by Louise Bourgeois. Her work is renowned for its personal content involving the unconscious, sexual desire, and the body, often drawing on events from her childhood. Bourgeois transformed these experiences into a visual language using objects such as spirals, spiders, cages, medical tools, and sewn appendages to symbolize the feminine psyche, beauty, and psychological pain (The Art Story Contributors n.d.). This extended to her holograms, which became an extrapolation of her approach to art and philosophical preoccupations rather than intended as original concepts specific to the strengths of the technology. In these holograms, Bourgeois had been working with small dioramas that translated well to the technical demands of holography production.

In 2017 these holograms were shown at the Cheim Read Gallery in New York. Reinforcing negative perceptions, the gallery described the works as a spectacle rather than integral to the artist's ongoing oeuvre, "Bourgeois's compositions takes on the cold, sentient glow of an untrustworthy computer in a vintage Sci-fi film." Gifted from the Easton Foundation to the Museum of Modern Art (MOMA) in New York, holograms from the same series were exhibited in 2019 as part of the exhibition, "New Order: Art and Technology in the 21st Century." The curators' intention was to explore the nexus of where art meets technology in the 21st century. "Today, when technology seems utterly smooth and weightless-composed of invisible waves, wireless signals, abstract codes-New Order explores the 
ways in which these systems are still stubbornly tied to the physical world. Technology, they suggest, is always mired in matter" (Museum of Modern Art 2019). The marketing of these exhibitions to the public was profoundly different. If holography as an art form is to mature, its artistic integrity has to be paramount and supersede questions about the technology that creates it.

The Barron's gift of several Louise Bourgeois holograms from C-Project to The Detroit Institute of Art in 2018 and 105 holograms from the same project to the Getty Research Institute in Los Angeles introduce a seminal point of departure for the acquisition of holographic art and installation by other museums. These important donations to American museums are the most significant to date and acknowledge art holography as a legitimate medium of expression while providing fine art museums with name artists that strengthen their contemporary collections.

Other recent donations and acquisitions to art museums include Multiplex holograms by the Italian American choreographer and dancer, Simone Forti, who recognized the potential of this type of hologram where viewers could experience her dance in the round and began to collaborate with Lloyd Cross in the 1970s. Her focus was improvisational dance and her association with the Judson Dance Theater Group revolutionized dance in New York in the 1960s (Movement Research n.d.). Her "Striding Crawl," 1977, was acquired by the Whitney Museum of American Art in New York in 2003 while "Harmonics (3)," 1973-78, was collected by the Albright-Knox Art Gallery in Buffalo, New York this past year. This type of hologram, invented in 1973, is called an Integral Stereogram or multiplex hologram. It was an accessible technique where the subject was photographed on a turntable performing a motion. The frames of film were processed as vertical strips of information side by side on a large sheet of film. To reconstruct the dimensional image, the film would be mounted on a transparent cylinder and lit with a light bulb from underneath.

For many years one of the only fine art museums with a commitment to exhibiting and collecting artist's holograms and installations has been the Butler Institute for American Art in Youngstown, Ohio, and has exhibited and collected holograms by artists whose primary medium is holography. Separately, though not a museum, the Holocenter in New York has for over twenty years provided education, artist-in-residence programs and exhibitions highlighting fine art holography and installation works. The Museum of Modern Art in New York, Victoria and Albert Museum in London, England, the Australia National Gallery in Canberra, Australia, the Montreal Museum of Fine Art in Montreal, Canada are some of the international fine art museums that have collected holography by contemporary artists. In addition, the Hologram Foundation in Paris, France, provides financial assistance to artists and programs for the production of holograms. It is one of the only foundations that continue to underwrite art holography. For artists, conferences and published papers remain the primary platform for the critical examination of Art Holography.

\section{Conclusions}

The purpose of this paper was to discover whether holography as a medium for artistic expression had in the last few decades found its way into mainstream galleries and fine art museums. Initially, celebrated artists from various media including Salvador Dali, Bruce Nauman, James Turrell, Louise Bourgeois and Michael Snow amongst others were commissioned to collaborate on holographic works in an effort to bring artistic credibility and validation to the emerging technology. Artists who began their practice in collaboration with scientists often went on to create "labs" of their own and developed and extended the visual and physical language of art holography. Today a handful of fine art museum collections are accepting donations of these seminal artworks. Current representations by artists working in holography include gallery installations encompassing the broader parameters of the technology including holographic interferometry, light, video and laser projections. Taken together, while several private collections and museums have acquired holograms by artists in the decades since the $\mathrm{MOH}$ closed, the medium has not gained the foothold that would be expected of a visual art that has been in existence for over fifty years. 
Physically, the properties of holograms are not especially different from other sensitive material factors found in contemporary media art. The aforementioned considerations of caring for unstable gelatins, aging lasers, the unique requirements of archival storage, specific exhibition and lighting concerns are important contributing factors to a museum's acceptance of a donation but perhaps the greater paradox for museum curators continues to be the line between technological gimmickry and aesthetic value, hence the preference to collect established artists in other media who have made holograms as an extension of their oeuvre.

In time, art world curators will catch up with the existing wealth of holographic art as a specific genre and more than a means of augmenting existing photography collections. In time, the success of an artist's holographic work will not be whether it projects into deep space or shows unusually bright color or animation. The best fine art holograms will transcend their technology and imbue the viewer with a desire to look further in the same way that a sculpture seductively invites the viewer to move around the object to see all sides and experience the volume of the work as a whole. Artists say that creating images that lack material textures but are visible dimensionally as light cannot be compared to other media but that is exactly what is required-holograms and installations that take the medium for granted and stand up to all and any comparison.

Funding: This research has received no external funding.

Conflicts of Interest: The author declares no conflicts of interest.

\section{References}

Benyon, Margaret. 1994. How Is Holography Art? Ph.D. thesis, Royal College of Art, London, UK.

Chimera, Paul. n.d. "Holography was "New House of Creation" for Dali, The Salvador Dali Society. Available online: https://dali.com/holography-new-house-creation-dali/ (accessed on 10 August 2019).

Ganz, Jim. 2019. Los Angeles, Press Release. March 5. Available online: http://news.getty.edu/getty-museumannounces-donation-105-holograms-created-by-20-noted-artists.htm (accessed on 10 August 2019).

Johnston, Sean F. 2009. Why Display? Representing Holography in Museum Collections. In Illuminating Instruments. Edited by Peter Morris and Klaus Staubermann. Washington, DC: Smithsonian Institution.

Movement Research. n.d. Simone Forti. Available online: https://movementresearch.org/people/simone-forti (accessed on 10 August 2019).

Museum of Modern Art. 2019. New Order Art and Technology in the Twenty-First Century. New York: Museum of Modern Art, Available online: https://www.moma.org/calendar/exhibitions/5033?locale=en (accessed on 10 August 2019).

Prickett, Sarah Nicole. 2012. After the Summer of the Hologram, What's Next? Available online: https://www.theglobeandmail.com/arts/art-and-architecture/after-the-summer-of-the-hologramwhats-next/article4497013/ (accessed on 10 August 2019).

The Art Story Contributors. n.d. Louise Bourgeois Artist Overview and Analysis. Available online: https: //www.theartstory.org/artist/bourgeois-louise/ (accessed on 10 August 2019).

(C) 2019 by the author. Licensee MDPI, Basel, Switzerland. This article is an open access article distributed under the terms and conditions of the Creative Commons Attribution (CC BY) license (http://creativecommons.org/licenses/by/4.0/). 